mediastinum is extremely rare, and the risk of malignant transformation may be increased with a long-standing, mature teratoma.

\section{References}

1. Ulbright TM, Loehrer PJ, Roth LM, Einhorn LH, Williams SD, Clark SA. The development of non-germ cell malignancies within germ cell tumors. A clinicopathologic study of 11 cases. Cancer. 1984;54:1824-33.

2. Ahmed T, Bosl GJ, Hajdu SI. Teratoma with malignant transformation in germ cell tumors in men. Cancer. 1985;56:860-3.
3. Morinaga S, Nomori H, Kobayashi R, Atsumi Y. Well-differentiated adenocarcinoma arising from mature cystic teratoma of the mediastinum (teratoma with malignant transformation): report of a surgical case. $A m$ J Clin Pathol. 1994;101:531-4.

4. Jung JI, Park SH, Park JG, Lee SH, Lee KY, Hahn ST. Teratoma with malignant transformation in the anterior mediastinum: a case report. Korean J Radiol. 2000;1:162-4.

5. Chadha S, Schaberg A. Malignant transformation in benign cystic teratomas: dermoids of the ovary. Eur J Obstet Gynecol Reprod Biol. 1988; 19:329-38.

\title{
Carcinoid tumor nested within a bronchogenic cyst
}

\author{
Elliot Servais, MD, Subroto Paul, MD, Jeffrey L. Port, MD, Nasser K. Altorki, MD, and Paul C. Lee, MD, New York, NY
}

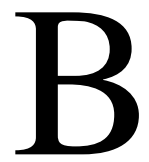

ronchogenic cysts are congenital lesions of the embryonic foregut. First described in 1859 by Meyer, ${ }^{1}$ these anomalies are believed to arise from supernumerary or abnormal budding of the tracheobronchial tree. These cysts, which often remain asymptomatic, are brought to clinical attention after incidental discovery on chest radiography or owing to complications such as infection, compression, and, rarely, hemorrhage or rupture. However, a less widely recognized phenomenon is occult neoplastic disease within the cyst wall. Herein, we describe a case of a carcinoid tumor within the wall of a resected bronchogenic cyst.

\section{Clinical Summary}

A 54-year-old woman had shortness of breath and chest tightness for 5 weeks. She reported a history of hypertension, mitral valve prolapse, and basal cell carcinoma of the right thigh. She had a 15 pack-year smoking history but had quit 5 weeks earlier. Results of the physical examination were unremarkable, with no cardiopulmonary abnormalities. Subsequent workup with a chest radiograph demonstrated a mediastinal mass. Concomitant chest computerized tomography $(\mathrm{CT})$ scan showed a $5.8 \times 5.8$-cm cystic mass in the superior middle mediastinum (Figure $1, A$ ). Subsequent chest magnetic resonance imaging (MRI) confirmed the cystic nature of the

From the Division of Thoracic Surgery, Department of Cardiothoracic Surgery, New York Presbyterian Hospital, Weill Medical College of Cornell University, New York, NY.

Received for publication Dec 9, 2007; accepted for publication Feb 5, 2008.

Address for reprints: Paul C. Lee, MD, Division of Thoracic Surgery, Department of Cardiothoracic Surgery, New York Presbyterian Hospital, Medical College of Cornell University, New York, New York 10021 (E-mail: pc19001@med.cornell.edu).

J Thorac Cardiovasc Surg 2008;136:227-8

$0022-5223 / \$ 34.00$

Copyright (C) 2008 by The American Association for Thoracic Surgery doi:10.1016/j.jtcvs.2008.02.042 mass with T2-weighted images demonstrating the cyst to be fluid filled as suspected on chest CT. Chest MRI did not reveal any communication with the esophagus (Figure $1, B$ ). These findings were consistent with a diagnosis of bronchogenic cyst.

The patient was taken to the operating room where a right thoracotomy was performed. Exploration revealed the cystic mass to be adherent to the trachea with surrounding inflammation and scar tissue. The cystic mass was freed from the trachea and surrounding mediastinal tissue. Resection was facilitated after aspiration of the cyst's fluid contents. Postoperatively, she had an uncomplicated course and was discharged from the hospital on postoperative day 4 . Subsequent pathologic evaluation of the specimen revealed a bronchogenic cyst with typical carcinoid tumor nested within the cyst wall (Figure 1,C and $D$ ). The patient remains well 3 months postoperatively and will undergo no further treatments for carcinoid other than periodic surveillance.

\section{Discussion}

Bronchogenic cysts are the most common cystic lesions of the mediastinum. The incidence of symptoms varies from $30 \%$ to $70 \%{ }^{2}$ occurring most commonly owing to infectious or compressive causes. It has become standard management to resect symptomatic bronchogenic cysts. More important, perhaps, is the widely accepted policy of resection for incidentally discovered, asymptomatic cysts as well.

A retrospective review in 1996 by Ribet, Copin, and Gosselin ${ }^{3}$ supported the notion of resection for asymptomatic disease, suggesting that late complications outweigh the "acceptable morbidity" of resection. Malignant transformation of the cyst wall has also been described. Case reports have demonstrated squamous cell carcinoma, adenocarcinoma, and leiomyosarcoma arising from the bronchogenic cyst wall. ${ }^{2}$ In this report, we describe a case of carcinoid tumor occurring within the wall of a bronchogenic cyst. This is the second case of its kind reported in the English literature - the first was described by Greenfield and Howe ${ }^{4}$ in 1965.

Bronchial carcinoids fall within a spectrum of pulmonary neuroendocrine tumors ranging from typical carcinoid, characterized by an 


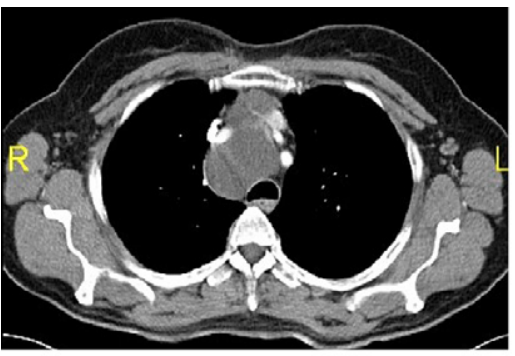

A

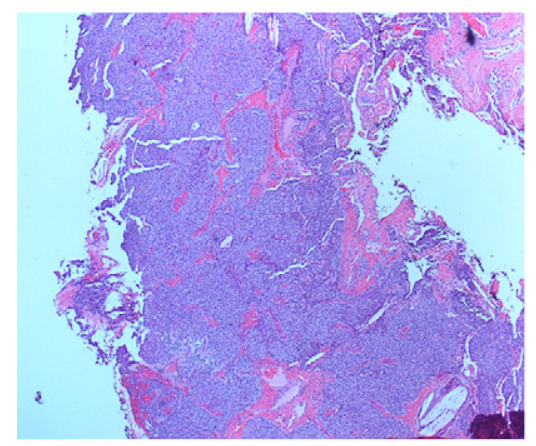

C

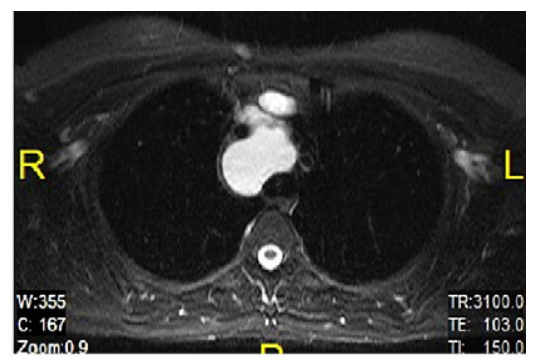

B

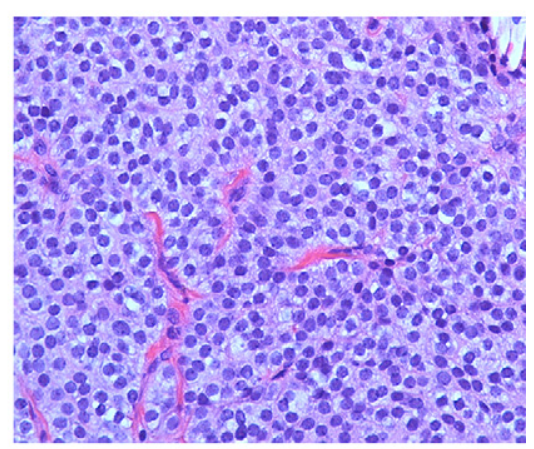

D
Figure 1. A, Chest CT illustrating mediastinal cyst bordering right tracheobronchial tree consistent with bronchial cyst. B, T2-weight images on chest MRI demonstrating fluid component within cyst. C, Lower-power view of hematoxylin and eosinstained cyst wall demonstrating typical carcinoid tumor nested within cyst wall. D, High-power view of hematoxylin and eosin-stained cyst wall illustrating typical carcinoid tumor cells. indolent clinical course with low metastatic potential, to high-grade tumors such as small cell lung cancer. Atypical carcinoids demonstrate an intermediate behavior. Importantly, in the case of completely resected typical carcinoid (as in the current report), there appears to be no role for adjuvant therapy given the uniformly favorable prognosis.

Various techniques are described in the surgical management of mediastinal bronchogenic cysts. ${ }^{5}$ Thoracotomy remains the standard approach. However, additional options include simple cyst aspiration, mediastinoscopy for lesions in the paratracheal location, and increasingly video-assisted thorascopic approaches. The surgeon should recognize, however, that incomplete removal runs the risk of leaving behind neoplastic disease in the cyst wall, as illustrated by the current case report.

In conclusion, we describe a rare case of typical carcinoid tumor within the wall of a bronchogenic cyst. This case highlights the potential for occult neoplastic disease within a bronchogenic cyst wall and lends support to a policy of resection for symptomatic and asymptomatic disease alike.

\section{References}

1. Meyer H. Uber angeborene blasige Missbildung der Lungen, nebst einigen Bemerkungen uber Cyanose aus Lungenleiden. Archiv Pathol Physiol Klin Med. 1859;16:78-95.

2. Cuypers P, De Leyn P, Cappelle L, Verougstraete L, Demedts M, Deneffe G. Bronchogenic cysts: a review of 20 cases. Eur J Cardiothorac Surg. 1996;10:393-6.

3. Ribet ME, Copin MC, Gosselin BH. Bronchogenic cysts of the lung. Ann Thorac Surg. 1996;61:1636-40.

4. Greenfield LJ, Howe JS. Bronchial adenoma within the wall of a bronchogenic cyst. J Thorac Cardiovasc Surg. 1965;49:398-404.

5. Bolton JW, Shahian DM. Asymptomatic bronchogenic cysts: what is the best management? Ann Thorac Surg. 1992;53:1134-7. 